\title{
Design of Multisection Impedance-Matched Dielectric-Slab Filled Waveguide Phase Shifters
}

\author{
FRITZ ARNDT, SENIOR MEMBER, IEEE, JENS BORNEMANN, AND RÜDIGER VAHLDIECK
}

\begin{abstract}
Optimum-matched dielectric-slab filled waveguide phase shifters are designed with the method of field expansion into eigenmodes, which includes higher order mode interaction between the step discontinuities. The relative phase shift is mechanically adjustable between $0^{\circ}$ and about $360^{\circ}$ at midband frequency by lateral displacement of the dielectric slab. Computer-optimized design data are given for $K u-, K$-, and $K a$-band prototypes which achieve return losses of better than $40 \mathrm{~dB}$, both as a function of displacement at midband frequency and as a function of frequency at fixed displacements. Measurements verify the theory.
\end{abstract}

\section{INTRODUCTION}

$\mathrm{T}$ HE ASYMMETRICALLY dielectric-slab loaded waveguide phase-shifter type, which is the initial form of the following investigations, is an old design [1] extensively employed in the industry. Although its wavepropagation characteristics have been studied widely by many authors [1]-[6], there still exists a paucity of suitable theoretical research on the three-dimensional scattering problem of impedance matching to the unloaded waveguide sections. Available experimental design data and equivalent circuit designs theories (e.g., [2], [7], [8]) often lead to wrong results, since immediate higher order modecoupling effects cannot be taken into account there, directly.

This paper describes a field theory analysis of dielectricslab phase shifters with multi-section transformer ends (Fig. 1), which is based on field expansion into incident and scattered waves. This allows direct calculation of the scattering matrix and the immediate inclusion of higher order mode coupling, also below the corresponding cutoff frequency. Computer-aided design using this theory provides optimum low-input VSWR, both as a function of displacement $c$ of the slab at a given frequency and as a function of frequency at a fixed position of the slab. A $K u$-band phase-shifter prototype, which is fabricated with simple filing techniques using Rexolite for dielectric material, will verify the theory given.

\section{THEORY}

The three-dimensional step discontinuity problem of Fig. 2(b) contains no $y$-dependent distortion of the fields. If $\mathrm{TE}_{\mathrm{m} 0}$ waves are incident at $z=0, l_{1}, l_{2}$, etc., the only

Manuscript received February 7, 1983; revised July 5, 1983.

The authors are with the Microwave Department, University of Bremen, Kufsteiner Str., NW 1, 2800 Bremen, West Germany.

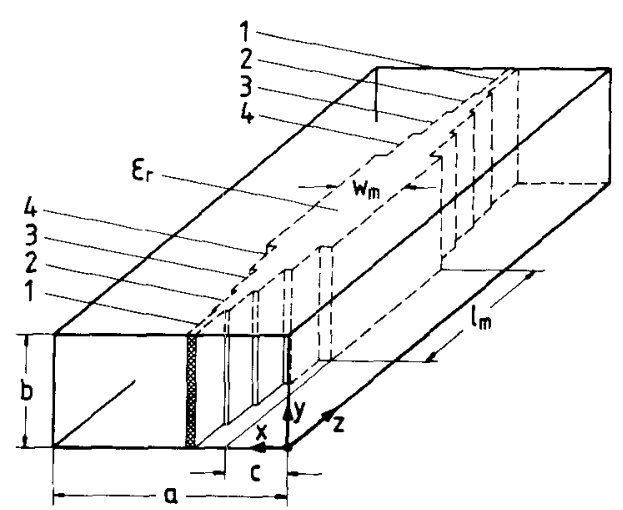

Fig. 1. Dielectric-slab phase shifter in the rectangular wavegude with four-step impedance-matching transformers at both ends.

modes directly excited are also $\mathrm{TE}_{\mathrm{m} 0}$ modes [9]-[12]. The analysis in this paper is, therefore, reduced to this case using the method of field expansion into suitable orthogonal eigenmodes [9]-[12]. Since the calculation corresponds partially to the fin-line filter analysis in [12], its description is abbreviated. For details, the reader is referred to [12].

For each subregion $\nu=$ I, II, III, and IV (Fig. 2), the fields

$$
\boldsymbol{E}^{(\nu)}=-j \omega \mu \nabla \cdot \Pi_{h x}^{(\nu)}, \quad \boldsymbol{H}^{(\nu)}=\nabla \times \nabla \times \Pi_{h x}^{(\nu)}
$$

are derived from the $x$-component of the magnetic Hertzian vector potential $\Pi_{h}$ which is assumed to be a sum of suitable eigenmodes satisfying the vector Helmholtz equation and the corresponding boundary conditions

$$
\begin{aligned}
\Pi_{h x}^{(I)}= & \sum_{m=1}^{\infty} A_{m}^{(I)^{ \pm}} \sin \frac{m \pi}{a} x \cdot e^{\mp \jmath k_{z m}^{(I I)} \cdot z} \\
\Pi_{h x}^{(I I)}= & \sum_{m=1}^{\infty} \mid B_{1 m}^{(I I)^{ \pm}} \cos \left(k_{x m}^{(I I)} \cdot x\right) \\
& +B_{2 m}^{(I I)^{ \pm}} \sin \left(k_{x m}^{(I I)} \cdot x\right) \mid \cdot e^{\mp J k_{z m}^{(I I)} \cdot z} \\
\Pi_{h x}^{(I I I)}= & \sum_{m=1}^{\infty} B_{m}^{(I I I)^{ \pm}} \mid-\tan \left(k_{x m}^{(I I I)} \cdot a\right) \cos \left(k_{x m}^{(I I I)} \cdot x\right) \\
& +\sin \left(k_{x m}^{(I I I)} \cdot x\right) \mid \cdot e^{\mp j k_{z m}^{(I I)} \cdot z} \\
\Pi_{h x}^{(I V)}= & \sum_{m-1}^{\infty} B_{m}^{(I V)^{ \pm}} \sin \left(k_{x m}^{(I V)} \cdot x\right) \cdot e^{\mp J k_{z m}^{(I I)} \cdot z} .
\end{aligned}
$$


(a)

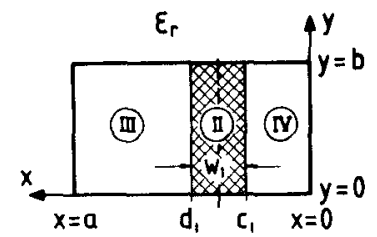

(b)

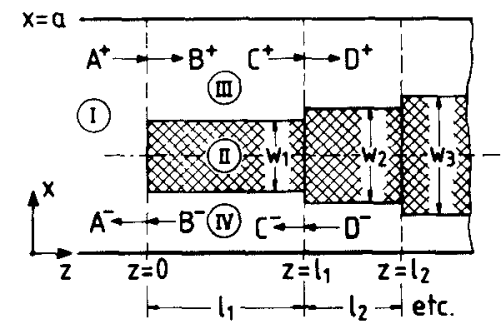

Fig. 2. Configuration for the field theory treatment. (a) Cross section of the dielectric-slab structure $i$. (b) Wave amplitude vectors of the structures of finite length.

$A_{m}^{(\nu) \pm}, B_{(1,2) m}^{(\nu \pm}$ are the still unknown eigenmode amplitudes of the forward and backward waves in the subregions ( $\nu$ ) which are suitably normalized so that the power carried by a given wave is proportional to the square of the wave amplitude coefficients.

By matching the field components at the corresponding interfaces of the adjacent subregions (Fig. 2(b)) at $z=0$, the coefficients $A_{m}^{(\nu)}$ and $B_{(1,2) m}^{(\nu)}$ in (2) can be determined after multiplication with the appropriate orthogonal function, related to each subregion [12]. This leads to the scattering coefficients of the step at $z=0$

$$
\left(\begin{array}{l}
(A)^{-} \\
(B)^{+}
\end{array}\right)=\left(\begin{array}{ll}
\left(Q_{11}\right) & \left(Q_{12}\right) \\
\left(Q_{21}\right) & \left(Q_{22}\right)
\end{array}\right)\left(\begin{array}{l}
(A)^{+} \\
(B)^{-}
\end{array}\right) .
$$

The scattering matrix of the structure of finite length $l_{1}$ is given by

$$
\left(\begin{array}{l}
(A)^{-} \\
(D)^{+}
\end{array}\right)=\left(\begin{array}{ll}
\left(S_{11}\right) & \left(S_{12}\right) \\
\left(S_{22}\right) & \left(S_{22}\right)
\end{array}\right)\left(\begin{array}{l}
(A)^{+} \\
(D)^{-}
\end{array}\right)
$$

with

$$
\begin{aligned}
\left(S_{11}\right) & =\left(S_{22}\right)=\left(Q_{11}\right)+\left(Q_{12}\right)(R)(W)\left(Q_{22}\right)(R)\left(Q_{21}\right) \\
\left(S_{12}\right) & =\left(S_{21}\right)=\left(Q_{12}\right)(R)(W)\left(Q_{21}\right) \\
(W) & =\left((U)-\left(Q_{22}\right)(R)\left(Q_{22}\right)(R)\right)^{-1} \\
(U) & =\text { unit matrix }
\end{aligned}
$$$$
R_{m m}=e^{-j k_{m m}^{(I I)} \cdot l_{1}} \text { (diagonal matrix of the waveguide section }
$$
between the discontinuities).

The scattering matrix of two and more sections, Fig. 2(b), is calculated by directly combining the involved scattering matrices [12], which preserves numerical accuracy, in contrast to the common treatment by transmission matrix parameters.

An optimizing computer program is used, based on the evolution strategy method [13], which requires no differentiation step in the optimizing process. For given waveguide housing dimensions, number of transformer sections, (a)

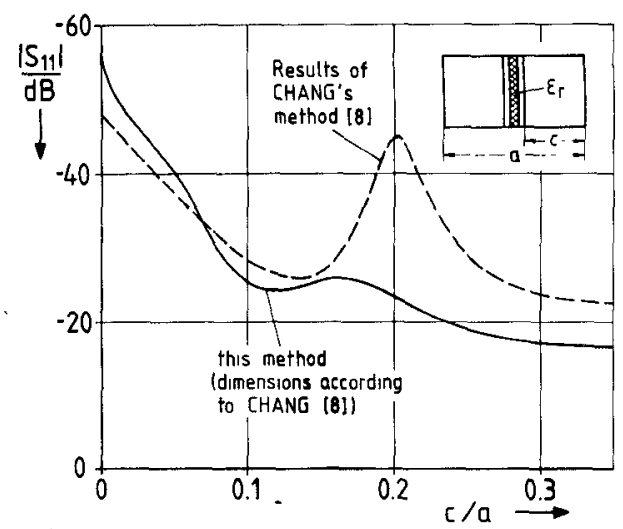

(b)

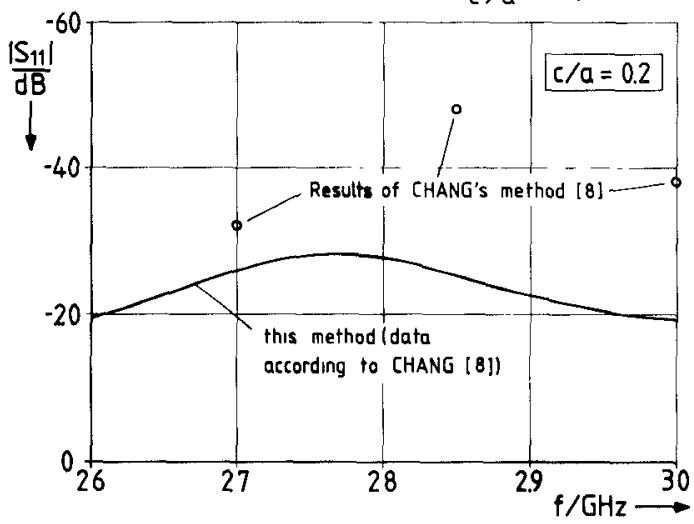

Fig. 3. One-section transformer phase shifter. Comparison of the input reflection factor ( $\left|S_{11}\right|$ in decibels, return loss) calculated by this method ( - solid line) and by the equivalent circuit approach of Chang [8] ( ---- dashed line, reproduction from [8]). Data according to Chang [8]: $a=72.136 \mathrm{~mm}, b=36.680 \mathrm{~mm}$; transformer section $l_{1}=32$ $\mathrm{mm}, w_{1}=1.799 \mathrm{~mm}$; phase-shifter section $l_{m}=134.85 \mathrm{~mm}, w_{m}=3.607$ $\mathrm{mm} ; \epsilon_{r}=8.2$. (a) $\left|S_{11}\right|$ as a function of normalized displacement $c / a$ at $f_{0}=2.85 \mathrm{GHz}$. (b) $\left|S_{11}\right|$ as a function of frequency at $c / a=0.2$.

relative dielectric constant of the slab, and desired approximate maximum phase-shift difference ${ }^{1}$ at midband (which fixes the width $w_{m}$ and the length $l_{m}$ of the middle section of the dielectric-slab phase shifter, cf. Fig. 1), the parameters $l_{1}$ to $l_{n}$ (lengths), and $w_{1}$ to $w_{n}$ (widths of the $n$ transformer sections, cf. Figs. 1 and 2(b)) were varied until the input reflection coefficient is of a minimum for a given frequency, both as a function of displacement and (at a fixed displacement, e.g., for relative midband phase shifts of about $180^{\circ}$ and $360^{\circ}$ ) as a function of frequency within a given bandwidth.

For computer optimization, the expansion into ten eigenmodes at each discontinuity has turned out to be sufficient. The final design data are proved by expansion into fifteen eigenmodes. The total time for the optimization of one set of phase-shifter parameters was about $30 \mathrm{~min}$ with a SIEMENS-7880 computer.

\section{RESULTS}

Fig. 3 compares the input reflection coefficient $\left|S_{11}\right|$ in decibels (return loss) as a function of normalized displacement $c / a$ and of frequency of the one-step matched phase

\footnotetext{
${ }^{1}$ The phase-shift difference $\Delta \varphi$ of the designed waveguide phase shifters is related to the lateral displacement $c=0$, cf. Fig. 1: For $c=0$ is $\Delta \varphi=0$, for $c=a / 2-\left(w_{m}\right) / 2$ is $\Delta \varphi=\Delta \varphi_{\max }$.
} 
TABLE I

COMPUTER-OPTIMIZED DESIGN DATA FOR MATChED FOUR-TRANSFORMER-SECTION Phase Shifters, Mechanically Adjustable for 0 To About $360^{\circ}$ Relative Midband Phase Shift $\left(\epsilon_{r}=2.54\right.$, ReXolite)

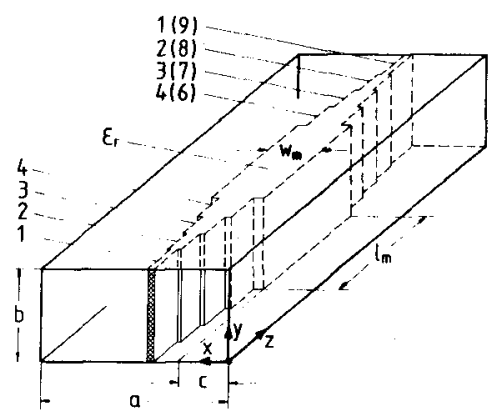

\begin{tabular}{|c|c|c|c|c|c|c|c|c|}
\hline $\begin{array}{c}\text { Frequency } \\
\text { - band } \\
\text { Waveguide } \\
\text { housing }\end{array}$ & 1 & $\begin{array}{l}\text { ransformer S } \\
1=\text { Ien } \\
w=\text { wid } \\
2\end{array}$ & $\begin{array}{lc}\text { tep } & \text { dimension } \\
\text { gth } & (\mathrm{mm}) \\
\text { th } & (\mathrm{mm}) \\
& 3\end{array}$ & 4 & $\begin{array}{l}\text { Mean section } \\
\text { the dielectric } \\
\text { slab } \\
l_{n}, W_{n}(\mathrm{~mm})\end{array}$ & $\begin{array}{l}\text { Midtand } \\
\text { frequency } \\
\left(\mathrm{EHz}_{2}\right)\end{array}$ & $\begin{array}{l}\text { ₹40 dB } \\
\text { return loss } \\
\text { bandwidth } \\
\text { for } 350^{\circ} \\
\text { eioband ohase } \\
\text { shift ( GHz ) }\end{array}$ & Remarks \\
\hline \multirow{4}{*}{$\begin{array}{c}k u-b a n d \\
a=15.799 \mathbf{m} \\
b=7.899 \mathrm{~mm} \\
(\mathrm{WR} 62)\end{array}$} & $\begin{aligned} 1 & =8.243 \\
W & =0.384\end{aligned}$ & $\begin{array}{l}l=7.745 \\
w=1.296\end{array}$ & $\begin{array}{l}1=7.129 \\
H=2.366\end{array}$ & $\begin{array}{l}I=6.630 \\
w=3.302\end{array}$ & $\begin{array}{l}\mathrm{l}_{\mathrm{n}}=44.240 \\
\mathrm{~m}=3.700\end{array}$ & 13 & 1.5 & 1) \\
\hline & $\begin{array}{l}1=8.0 \\
W=0.6\end{array}$ & $\begin{array}{l}1=7.3 \\
w=1.8\end{array}$ & $\begin{array}{l}1=6.6 \\
*=3.0\end{array}$ & $\begin{array}{l}l=6.0 \\
w=4.2\end{array}$ & $\begin{array}{l}l_{1}=61.2 \\
u_{1}=5.0\end{array}$ & 13 & 1.0 & 2) \\
\hline & $\begin{array}{l}l_{1}=7.995 \\
*_{1}=0.47\end{array}$ & $\begin{array}{r}\mathrm{I}_{2}=7.305 \\
*_{2}=1.705\end{array}$ & $\begin{array}{l}\mathbf{I}_{3}=6.625 \\
w_{3}=2.94\end{array}$ & $\begin{aligned} I_{4} & =6.0 \\
w_{4} & =4.15\end{aligned}$ & $I_{n}=61.2$ & \multirow{2}{*}{13.175} & \multirow{2}{*}{$\begin{array}{c}0.2 \\
\geqslant 30 \mathrm{dE}: \\
0.7\end{array}$} & \multirow{2}{*}{ 3) } \\
\hline & $\begin{array}{r}t_{9}=8.085 \\
H_{9}=0.575\end{array}$ & $\begin{array}{l}l_{B}=7.285 \\
H_{B}=1.815\end{array}$ & $\begin{array}{l}l_{7}=6.55 \\
y_{7}=2.97\end{array}$ & $\begin{array}{l}I_{6}=6.0 \\
w_{6}=4.19\end{array}$ & $w_{m}=4.975$ & & & \\
\hline $\begin{array}{c}K-\text { band } \\
a=10.668 \mathrm{~mm} \\
b=4.318 \mathrm{~mm} \\
(W \quad 42)\end{array}$ & $\begin{array}{l}L=4.699 \\
w=0.286\end{array}$ & $\begin{array}{l}l=4.431 \\
w=0.92\end{array}$ & $\begin{array}{l}I=4.099 \\
W=1.628\end{array}$ & $\begin{array}{l}l=3.831 \\
W=2.238\end{array}$ & $\begin{array}{l}I_{m}=29.88 \\
w_{m}=2.5\end{array}$ & 21 & 2.3 & 11 \\
\hline $\begin{array}{c}k a-\text { band } \\
a=7.112 \text { man } \\
b=3.556 \text { min } \\
(\text { W } 28)\end{array}$ & $\begin{array}{l}l=3.414 \\
v=0.194\end{array}$ & $\begin{array}{l}1=3.163 \\
=0.646\end{array}$ & $\begin{array}{l}1=2.852 \\
w=1.200\end{array}$ & $\begin{array}{l}l=2.600 \\
w=1.742\end{array}$ & $\begin{array}{l}l_{m}=24.50 \\
w_{m}=2.0\end{array}$ & 30 & 2.8 & 1) \\
\hline
\end{tabular}

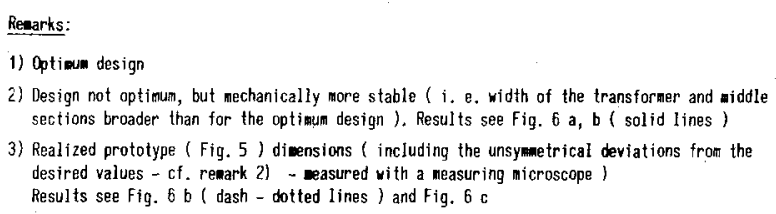

shifter according to Chang $[8]^{2}$ calculated by our method (solid line) with available results of the equivalent circuit approach of [8]. As expected, the theoretical results given in [8] differ considerably from our results, since the higher order mode interaction, included in our method, influences above all the input reflection behavior. Moreover, the one-step transformer of Chang shows return losses of typically only 20 to $30 \mathrm{~dB}$. Better return loss behavior is achieved by multisection transformers.

The investigation of multistep matched phase shifters with regard to the number of sections shows that four-section transformers yield a good compromise between appropriate return-loss behavior and design efforts. There-

\footnotetext{
${ }^{2}$ Chang's one-step phase-shifter design is based on an absolute phase shift between the input and the output port. This is in contrast to the relative phase-shift difference used in the design of this paper (which inlcudes the phase shift of the waveguide together with the dielectric slab for a displacement $c=0$ ). ${ }^{1}$ Chang's absolute phase shift corresponds only to a corresponding smaller relative phase shift.
}

fore, the data of computer-optimized four-section matched $360^{\circ}$ phase shifters for $K u$-, $K$-, and $K a$-band frequency examples are given in Table I. Rexolite (Styrol Polymerisate Compound; Atlantic Laminates, Franklin, NH 03285; $\epsilon_{r}=2.54$ ) has been selected for dielectric material because it is relatively easy to handle mechanically. For the computer optimization, the limit of tolerated minimum return loss is chosen to be $40 \mathrm{~dB}$. Higher values seem to be unrealistic since in practical designs mechanical tolerances cause, typically, return losses of a similar level which would mask the theoretical predicted behavior. Possible mechanical holders are not considered in the design.

Fig. 4 shows the results of an optimized $\mathrm{Ka}$-band phase shifter for design example (cf. Table I). There are indicated the relative phase shift $\Delta \varphi$ (Fig. 4(a)) and the input reflection coefficient $\left|S_{11}\right|$ in decibels (Fig. 4(b)) at midband frequency $f_{0}=30 \mathrm{GHz}$ as a function of normalized displacement $c / a$. In Fig. 4(c), the input reflection coefficient $\left|S_{11}\right|$ in decibels is shown as a function of frequency for two 
(a)

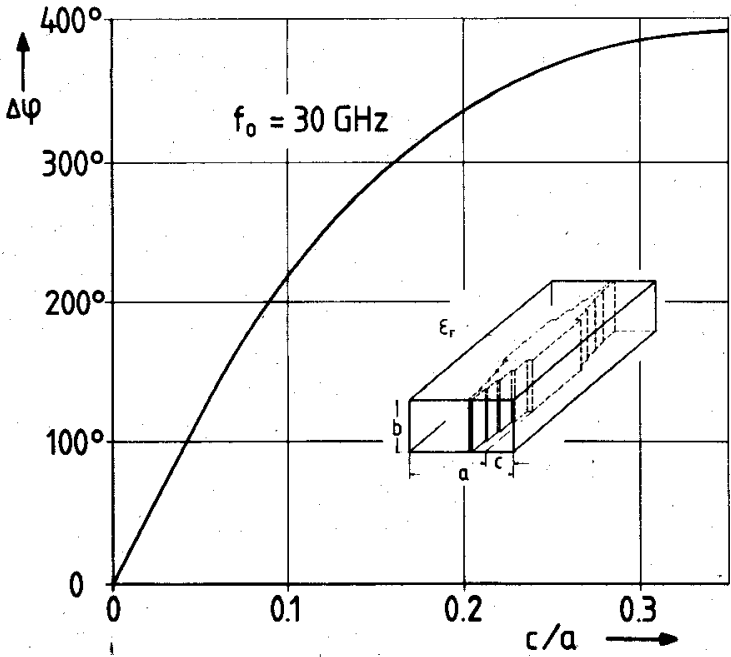

(b)

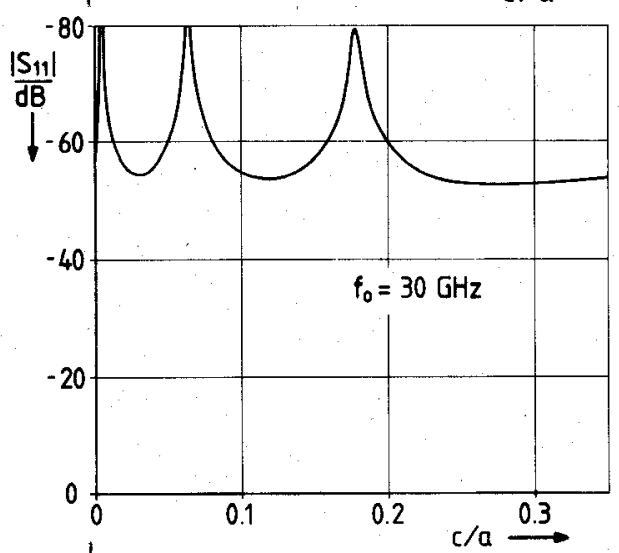

(c)

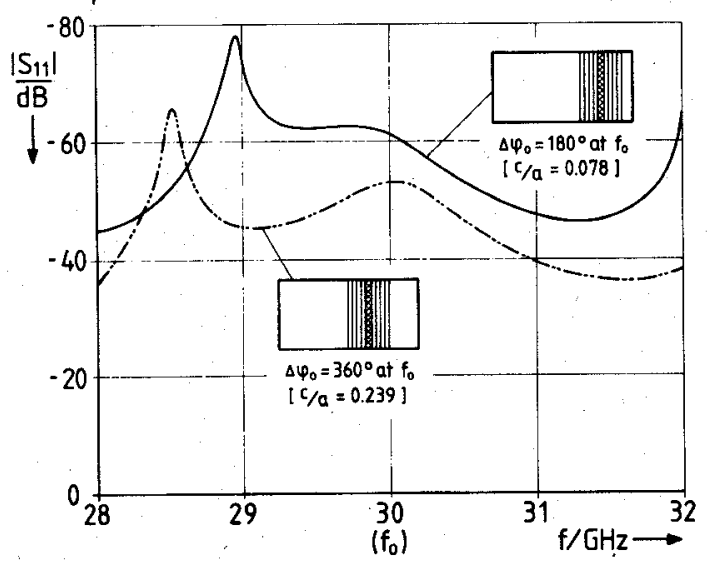

Fig. 4. Optimum $K a$-band phase shifter designed for $f_{0}=30 \mathrm{GHz}$ (cf. Table I). (a) Relative phase shift $\Delta \varphi$ as a function of normalized displacement $c / a$ at midband frequency $f_{0}=30 \mathrm{GHz}$. (b) Input reflection coefficient $\left|S_{11}\right|$ in $\mathrm{dB}$ (return loss) as a function of normalized displacement $c / a$ at midband frequency $f_{0}=30 \mathrm{GHz}$. (c) Input reflection coefficient $\left|S_{11}\right|$ in $\mathrm{dB}$ as a function of frequency for two typical relative phase-shift values at midband frequency $\left(\Delta \varphi_{0}=180^{\circ}, c / a=\right.$ $0.078 ; \Delta \varphi_{0}=360^{\circ}, c / a=0.239$ ).

typical relative phase-shift values $\Delta \varphi_{0}\left(180^{\circ}\right.$ and $\left.360^{\circ}\right)$ as a displacement parameter $c / a$ at midband frequency $f_{0}$. Within the whole displacement range $c / a=0, \cdots, 0.35$, and for a frequency range of about $3 \mathrm{GHz}$, the minimum return loss is more than $40 \mathrm{~dB}$.

A $K u$-band shifter prototype has been realized (Fig. 5) by simple filing techniques, where the maximum deviation

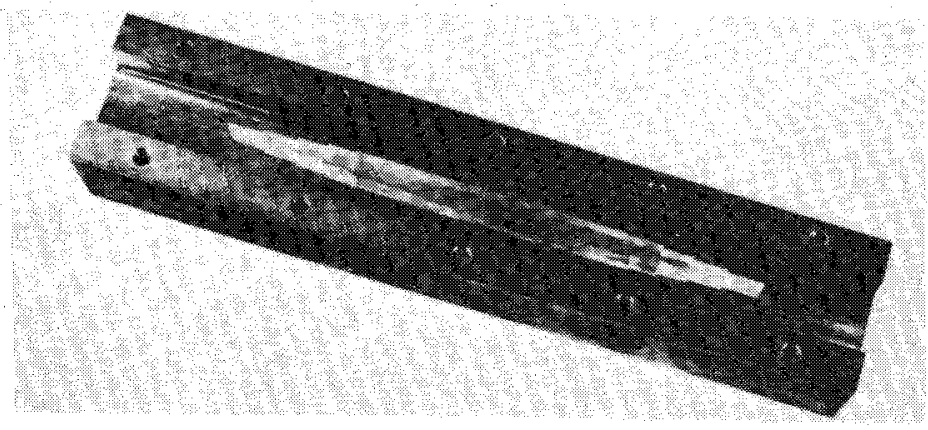

Fig. 5. Photograph of the realized $K u$-band phase-shifter prototype (cf. Table I, remark 3), Fig. 6.) (WR 62 waveguide housing, dielectric material: Rexolite, $\epsilon_{r}=2.54$ ).

from the desired values is about $-130 \mu \mathrm{m}$ (checked up by a measuring microscope, cf. Table I, remark 3)). The influence of these geometrical tolerances on the relative phase shift $\Delta \varphi$ is less than the drawing accuracy (Fig. 6(a)). The influence on the input reflection coefficient, however, is quite evident (Fig. 6(b)), solid line versus dash-dotted line). The mean deviation of the two theoretical input reflection coefficients is about $10 \mathrm{~dB}$. Nevertheless, in spite of these geometrical deviations, the input reflection coefficient is better than $34 \mathrm{~dB}$, which is within $c / a=0, \cdots, 0.35$. With better production techniques, which would hold the tolerance within about $\pm 0.01 \mathrm{~mm}$, the theoretical predicted return losses may be realized with values typically better than $40 \mathrm{~dB}$, as has been checked by using these geometrical tolerances in the theory. In Fig. 6, the measurements demonstrate good agreement between theory (for real prototype dimensions) and practical results. The remaining small difference between theory and measurements is due to the slight deviation of the realized dielectric-slab sections from the desired position parallel to the waveguide walls.

\section{CONCLUSION}

A computer-aided design of multisection impedancematched dielectric-slab-filled waveguide phase shifters is introduced, which enables the inclusion of higher order mode coupling effects in the computations. Application of the evolution strategy method leads to optimum low return losses ( $\geqslant 40 \mathrm{~dB}$ ), both as a function of displacement of the slab (for mechanically adjustable phase shift) at a given frequency, and as a function of frequency at a fixed position of the slab. Matched phase-shifter design data are given for $K u$-, $K$-, and $K a$-band prototypes. To verify the theory, a $K u$-band phase-shifter prototype is realized by simple filing techniques where the maximum geometrical deviation from the theoretical design data is about -130 $\mu \mathrm{m}$. This prototype achieves measured minimum return losses of about $36 \mathrm{~dB}$ as a function of displacement, and more than $34 \mathrm{~dB}$ and $31 \mathrm{~dB}$, as a function of frequency within $0.7-\mathrm{GHz}$ bandwidth, for midband phase-shift values $\Delta \varphi_{0}=236^{\circ}$ and $\Delta \varphi_{0}=364^{\circ}$ as parameters, respectively. Rexolite $\left(\epsilon_{r}=2.54\right)$ is chosen for dielectric material because it is easy to handle mechanically by the filing process 


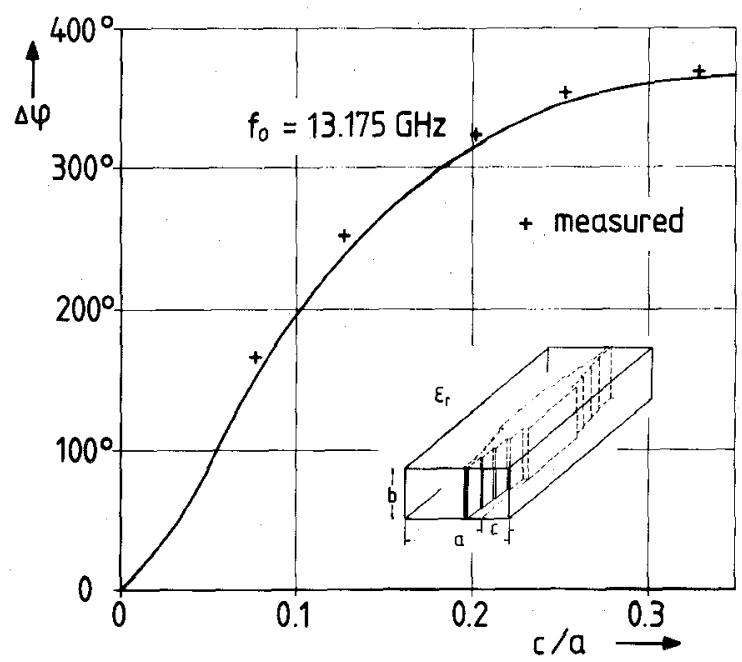

(a)

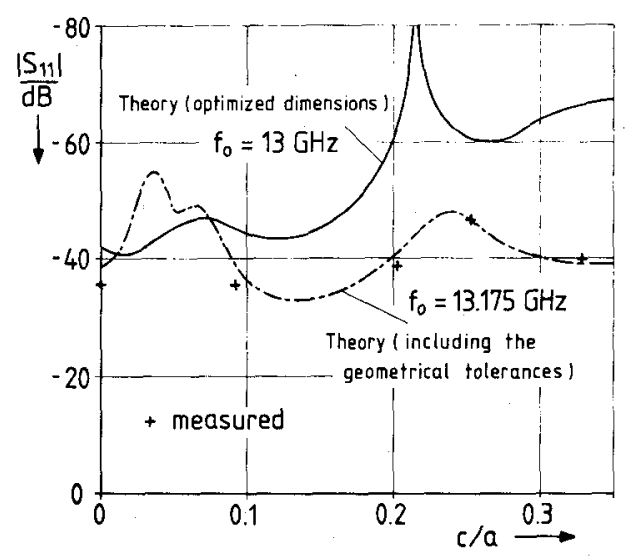

(b)

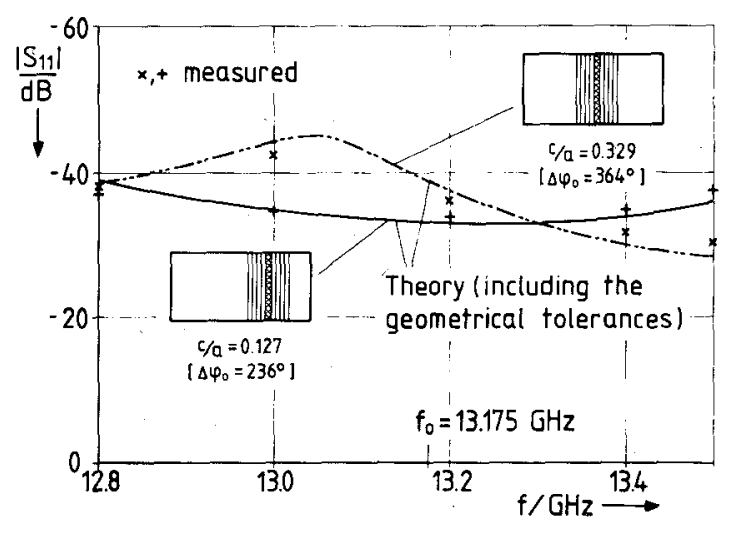

(c)

Fig. 6. Comparison of theory and measurements for the $K u$-band phase-shifter prototype (Table I, remarks 2) and 3)). (a) Relative phase shift $\Delta \varphi$ as a function of normalized displacement $c / a$ at midband frequency $f_{0}=13.175 \mathrm{GHz}$. (b) Input reflection coefficient $\left|S_{11}\right|$ in $\mathrm{dB}$ (return loss) as a function for normalized displacement $c / a$ at midband frequency $f_{0}=13 \mathrm{GHz}$. — optimized dimensions, (cf. Table I), second $K u$-band design. ..... realized dimensions including the geometrical deviations, measured by a measuring microscope (cf. Table I, remark 3). (For Fig. 6(a), the difference between the solid and dash-dotted line is less than the drawing accuracy.) (c) Input reflection coefficient $\left|S_{11}\right|$ in decibels as a function of frequency for two normalized displacement values $c / a=0.127\left(\Delta \varphi_{0}=236^{\circ}\right), c / a=0.329\left(\Delta \varphi_{0}\right.$ $=364^{\circ}$ ), as parameters. The theory corresponds to the realized phaseshifter prototype dimensions and includes the geometrical deviations. used. Production techniques with more technical efforts (e.g., punching or grinding process instead of simple filing techniques) together with, for these techniques, more adequate dielectric materials (e.g., alumina or quartz) may provide still better practical results.

\section{ACKNOWLEDGMENT}

This work is dedicated to Prof. Dr.-Ing. habil. O. Zinke, University of Darmstadt, W.-Germany.

\section{REFERENCES}

[1] N. Marcuvitz, Waveguide Handbook. New York: McGraw-Hill, 1951, pp. 224-248.

[2] R. E. Collin, Field Theory of Guided Waves. New York: McGrawHill, 1960.

[3] __ Foundations for Microwave Engineering. New York: McGraw-Hill, 1966.

[4] F. E. Gardiol, "Higher-order modes in dielectrically loaded rectangular waveguides," IEEE Trans. Microwave Theory Tech., vol. MTT-16, pp. 919-924, Nov. 1968.

[5] G. N. Tsandoulas, D. H. Temme, and F. G. Willwerth, "Longitudinal section mode analysis of dielectrically loaded rectangular waveguides with application to phase shifter design," IEEE Trans. Microwave Theory Tech., vol. MTT-18, pp. 88-95, Feb. 1970.

[6] C.-T. Liu and C. H. Chen, "A variational theory for wave propagation in inhomogeneous dielectric slab loaded waveguides," IEEE Trans. Microwave Theory Tech., vol. MTT-29, pp. 805-812, Aug. 1981 .

[7] G. P. Bava and C. Naldi,." Discussion of some design methods for dielectric steps in rectangular waveguides," IEEE Trans. Microwave Theory Tech., vol. MTT-18, pp. 167-168, Mar. 1970.

[8] C. T. M. Chang, "Partially dielectric-slab-filled waveguide phase shifter," IEEE Trans. Microwave Theory Tech., vol. MTT-22, pp. 481-485, May 1974.

[9] M. Hoffmann, "Die Streumatrix von Rechteckhohlleitungen mit magnetisierten Ferriteinsätzen endlicher Länge," Arch. Elek. Übertragung, vol. 32, pp. 62-68, 1978.

[10] J. Kruse and W. Engel, "Berechnung der Streumatrix verschiebbarer dielektrischer Stoffeinsätze in Rechteckhohlleitern," Diploma thesis, University of Bremen, Bremen, Germany, 1979.

[11] H. Chaloupka, "A coupled-line model for the scattering by dielectric and ferrimagnetic obstacles in waveguide," Arch. Elek. Übertragung, vol. 34, pp. 145-151, Apr. 1980 .

[12] F. Arndt, J. Bornemann, D. Grauerholz, and R. Vahldieck, "Theory and design of low-insertion-loss fin-line filters," IEEE Trans. Microwave Theory Tech., vol. MTT-30, pp. 155-163, Feb. 1982.

[13] H. Schmiedel, "Anwendung der Evolutionsoptimierung bei Mikrowellenschaltungen," Frequenz, vol. 35, pp. 306-310, Nov. 1980.

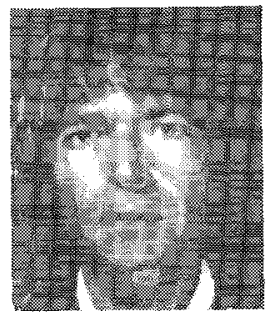

Fritz Arndt (SM'83) was born in Konstanz, Germany, on April 30, 1938. He received the Dipl.-Ing., Dr.-Ing., and Habilitation degrees from the Technical University of Darmstadt, Darmstadt, Germany, in 1963, 1968, and 1972, respectively.

From 1963 to 1972 , he worked on directional couplers and microstrip techniques at the Technical University of Darmstadt. Since 1972, he has been a Professor and Head of the Microwave Department at the University of Bremen, Bremen, Germany. His research activities are at present in the area of the solution of field problems of waveguide and fin-line structures and of antenna design.

Dr. Arndt is member of the VDE and NTG (Germany). In 1970, he received the NTG award. 


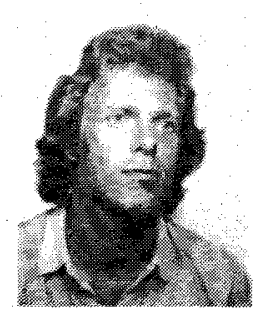

Jens Bornemann was born in Hamburg, West Germany, on May 26, 1952. He received the Dipl.-Ing. degree in electrical engineering from the University of Bremen, West Germany, in 1980.

Since 1980, he has been with the Microwave Department of the University of Bremen, where his research interests include discontinuities in waveguide structures, microwave integrated circuits, and numerical solutions of electromagnetic-field problems.

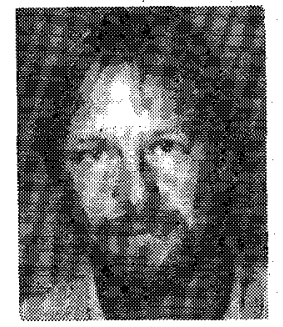

Rüdiger Vahldieck was born in Heiligenhafen, Germany, on July 8,1951 . He receive the Dipl.Ing. degree in electrical engineering from the University of Bremen, West Germany in 1980.

Since 1980 , he has been with the Microwave Department of the University of Bremen, where his present research activities are in the field of microwave integrated circuits and in solving electromagnetic-field problems for several waveguide discontinuities.

\title{
Rectangular Bars Coupled Through a Finite-Thickness Slot
}

\author{
J. H. CLOETE, MEMBER, IEEE
}

\begin{abstract}
A rigorous new solution, based on fringing capacitances and conformal mapping, is presented for the coupling problem in the parallel-coupled TEM transmission-line structure formed by two rectangular bars coupled through a rectangular slot, cut longitudinally in a finite-thickness ground plane. The conformal mapping solution is summarized in Appendix $I$ and is based on the procedure published by Getsinger [1]. Graphs of the capacitances needed to calculate the coupling for a given physical geometry, without solving the complicated equations associated with the theoretical solution, are also presented. A measurement procedure and experimental results are presented which verify the accuracy of the theoretical coupling data.
\end{abstract}

\section{INTRODUCTION}

$\mathrm{T}$ HE TEM STRUCTURE with cross section shown in Fig. 1 is used in interdigital linear-phase filters [2] and directional couplers with weak coupling, for example. For these applications, it is necessary to have an accurate procedure for designing the slot width that will realize a desired coupling, for a geometry that is otherwise specified. The current status of the literature on this problem is reviewed below.

In 1958, Shimizu and Jones [3] published an approximate formula, valid for weak coupling and based on Bethe's small aperture theory, for the case where both the coupling plate and center conductors have zero thickness, i.e., $a=0$ and $t=0$. Although their formula is only valid for zerothickness slots, Shimizu and Jones argued that, for finite-

Manuscript received February 7, 1983; revised June 23, 1983. This work formed part of a Ph.D. dissertation in the Department of Electrical and Electronic Engineering at the University of Stellenbosch. The supervisor was Prof. J. A. G. Malherbe.

The author is with the Department of Electronic Engineering; University of Pretoria, Pretoria 0002, South Africa.
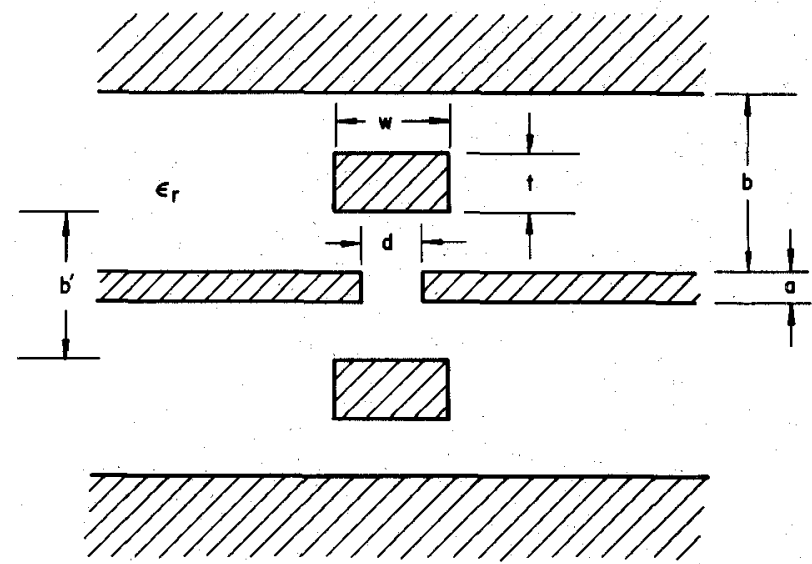

Fig. 1. Slot-coupled rectangular-bar geometry

thickness coupling plates, the slot acts as a waveguide below cutoff, and suggested the use of a simple correction term to take the effect of finite thickness into account.

Rhodes [2] invented the linear-phase filter and, in 1970, he used Shimizu and Jones' formula to compute the crosscoupling slot widths of rectangular-bar interdigital linearphase filters, and obtained good agreement between the theoretical and measured performance of 14 - and 18-element filters.

However, in 1976, Levy [4] stated that the early linearphase filters did not have good agreement between theory and experiment as far as the group-delay characteristics were concerned. The given reason was the failure to obtain the correct values for the cross couplings, due to the inadequate electromagnetic theories for the prediction of 